\title{
Mobility of Organic \\ Complexes of Some Non-TRU \\ Fission and Activation \\ Products: A Selective Review
}

by

D. J. Wiggins

J. A. Franz

Prepared for the

Nuclear Fuel Cycle and

Production Division of Department of Energy

Pacific Northwest Laboratory

Richland, Washington 99352

Operated for the

U.S. Department of Energy by 


\title{
NOTICE
}

This report was prepared as an account of work sponsored by the United States Covernment. Neither the United States nor the Department of Energy, nor any of their employees, aor any of their contrectors. subcontractors, or their employees, makes any warranty, express or implied, or assumes any legal liabitit: or responsibility for the accuracy, completeness or usefulness of any information apparatus, product ar preccsa disclosed, or represents that its use would not iniringe privately owned rights.

The views, opinions and conclusions contained in this report are those of the contractor and do no: necessarily represent those of the Unired States Government or the United States Denartment af Energy

\author{
PACIFIC NORTHWEST LABORATORY \\ operated by \\ BATTELLE \\ for the \\ UNITED STATES DEPARTMENT OF ENERGY \\ Under Contract EY-75-C-06-1830
}

\author{
Frinted in the Uni ed States of America. \\ Available from \\ National Technical Information Senvice \\ United States Department of Commerce \\ 5285 Port Royal Road \\ Springfield, Virginia 22151
}

Price: Printed Copy s_: Microfiche $\$ 3.00$

NTI5

*Fages Selling Price

$001-025 \quad 54.50$

$026.050=55.00$

$051-075 \quad 55.50$

$076-101=55.60$

$107-1255.50$

$125-150 \quad 57=00$

$151-275 \quad 5725$

$176 \cdot 200 \quad \$ 9.50$

207-225 $\quad$ S3.75

$226-230 \quad 5900$

$151.253 \quad \$ 10.00$

$276-360 \quad 510.25$ 


\section{6}

MOBILITY OF ORGANIC COMPLEXES OF SOME NON-TRU FISSION AND ACTIVATION PRODUCTS: A SELECTIVE REVIEW

by

D. J. Wiggins

J. A. Franz

Prepared for the Nuclear Fuel Cycle and Production Division of Department of Energy

May 1978

PACIFIC NORTHWEST LABORATORY

Richland, Washington 99352

Operated by

BATTELLE MEMORIAL INSTITUTE 


\section{CONTENTS}

LIST OF TABLES •

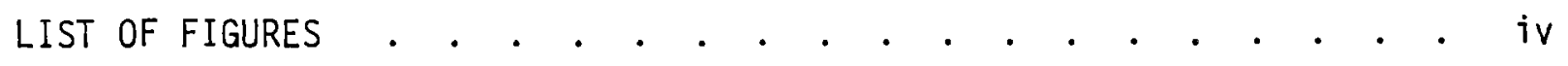

INTRODUCTION

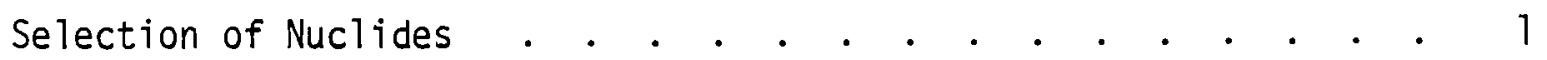

Structures and Mechanisms of Complexation by Organic Agents and

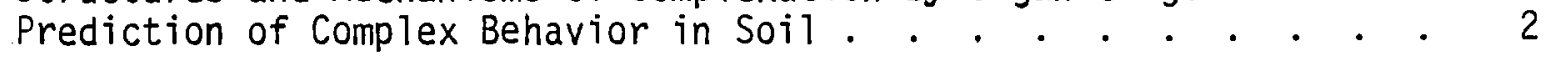

ZIRCONIUM-ORGANIC COMPLEXES

Aqueous Complex Stability . . . . . . . . . . . . . . 8

Aqueous Complex Stability in Soil Systems . . • . . . . . . . 13

NIOBIUM ORGANIC COMPLEXES

Aqueous Complex Stability . . . . . . . . . . . . . . . 16

Aqueous Complex Stability in Soil Systems . . . . . . . . . . 18

NICKEL-ORGANIC COMPLEXES

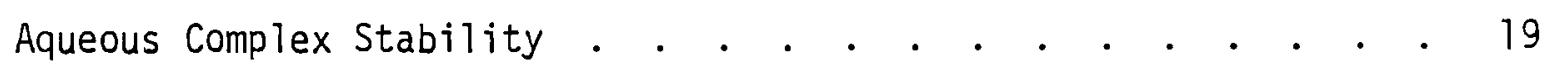

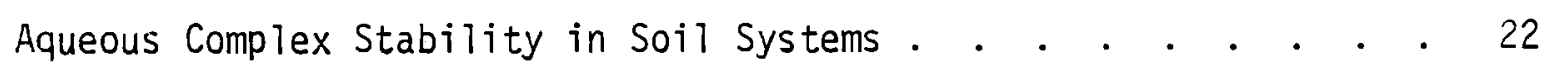

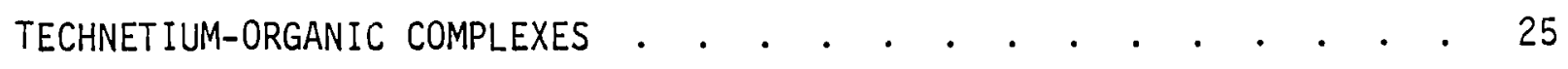

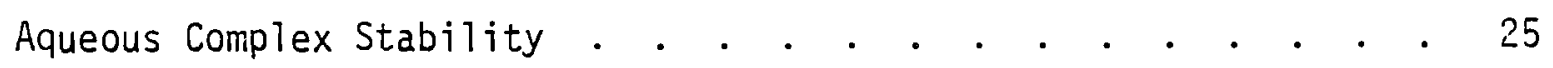

Aqueous Complex Stability in Soil Systems . . . . . . . . . . 26

SUMMARY • • • • • • • • • • • • • • • • • • • • • • • • 27

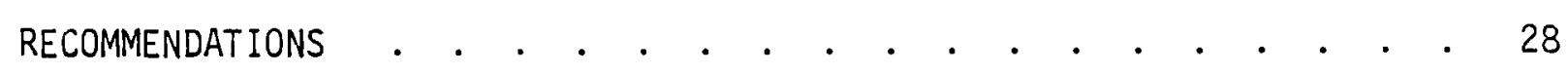

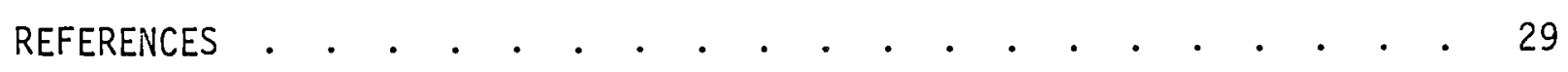

DISTRIBUTION 


\section{LIST OF TABLES}

1 Four Selected Isotopes, Their Half-lives, Decay Modes, Energies, and Principal Means of Production . . . . . . . . . . . 3

2 Classical Fractionation Scheme for Humus Matter of Soil . . . . 3

3 Stability Constants of Select Zirconium Complexes in Aqueous Solution. . . . . . . . . . . . . . . . . 10

4 Stability Constants of Select Niobium Complexes . . . . . . . 17

5 Stability Constants of Select Nickel Complexes in Aqueous Solution . . . . . . . . . . . . . . . . . 20

6 Stability Constants of Mixed Ligand Mixed Metal Ni Complexes . . 21

7 Stability Constants of Ni-Fulvic Acid Complexes . . . . . . . 24

8 Stability Constants of Technetium Complexes . . . . . . . 25

\section{LIST OF FIGURES}

1 Zirconium in Aqueous Solution at Varying Concentrations and pH . . 8

2 Probable Structure of $\mathrm{Zr}$-Tiron Complex and $\mathrm{Zr}$-Himda Complex According to Intorre and Martel1... . . . . . . . . . . 11

3 Zirconium Uptake by Calcareous Hanford Soils . . . . . . . . 14 


\section{MOBILITY OF ORGANIC COMPLEXES OF SOME NON-TRU}

FISSION AND ACTIVATION PRODUCTS:

A SELECTIVE REVIEW

\section{INTRODUCTION}

Probable increases in the volume of low-level radioactive waste produced by future expansion of the nuclear industry has prompted renewed interest in the burial of low-level waste in soil. Crucial to the storage of nontransuranic waste in shallow-land burial facilities is the successful isolation of isotopes from re-entry into the biosphere. It is now thought that organic constituents in soils play a much greater role in the transport of nuclides than previously recognized. To address this problem, this paper provides a selective review of the organic coordination chemistry and behavior in soil systems of organic complexes of zirconium, nickel, technetium, and niobium. This will be discussed in terms of interment of low-level nontransuranic waste in soil. This review will survey: sources of complexing agents and their structures; mechanisms of complex formation; the relevant coordination chemistry and soil behavior of complexes in soil; and recommend future research and methods for containment of radioactive isotopes.

\section{SELECTION OF NUCLIDES}

The selection of nuclides to be discussed here was based on identification of longer-lived isotopes generated in the nuclear fuel cycle which are currently present in burial grounds in significant quantities, $(1,2)$ and prediction of relative quantities of long-lived isotopes to be produced in the future provided by the ORIGEN-ORNL isotope generation and depletion code. ${ }^{\text {(3) }}$ since no prediction of low level waste is available, predictions for intermediatelevel waste were used to determine the important nuclides. ${ }^{(4)}$ In general, the predicted isotopes have half-lives of greater than ten years and are present in quantities greater than $0.1 \mathrm{Ci} /$ metric ton of spent PWR fuel after 200 years of depletion. 
Based on these criteria, ten isotopes comprise the most important non-TRU nuclides: ${ }^{90} \mathrm{Sr},{ }^{137} \mathrm{Cs},{ }^{154} \mathrm{Eu},{ }^{60} \mathrm{Co},{ }^{93} \mathrm{Zr},{ }^{63} \mathrm{Ni},{ }^{137} \mathrm{Ba},{ }^{151} \mathrm{Sm}$ and ${ }^{99} \mathrm{Tc}$. As more refined estimates of fuel cycle products and low-level storage become available, this list may require modification. $\mathrm{Zr}, \mathrm{Nb}, \mathrm{Ni}$ and $\mathrm{Tc}$ will be discussed in this paper and the other six selected isotopes will be discussed in succeeding papers. Table 1 lists the half lives, modes of decay and principal means of production.

STRUCTURES AND MECHANISMS OF COMPLEXATION BY ORGANIC AGENTS AND PREDICTION OF COMPLEX BEHAVIOR IN SOIL

There are two categories of mobile organic ligands or complexing agents: decomposing organic matter introduced as waste, and water mobile organic constituents, primarily humic and fulvic acids, present in the soil. (See Table 2) Waste-derived organic material buried in soil or "cribs" is highly varied and includes animal carcasses, low-level decontamination solutions, a wide variety of paper and rubber materials, and radioactive material packaged in a variety of metal, plastic and paper packing subject to decomposition.

The role of buried waste and soil organics in mobilizing $\mathrm{Zr}, \mathrm{Nb}, \mathrm{Ni}$, and Tc nuclides may be significant under favorable conditions. A water-saturated soil system with a relatively high soil organic content in the presence of buried waste nuclides could lead to effective complex formation and increased solubility and mobility of the buried waste nuclides. Other burial sites can offer an ideal combination of retention conditions such as almost no rain

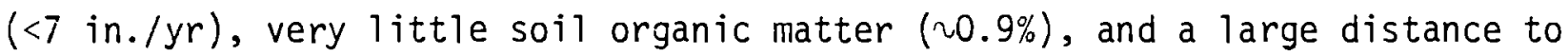
the ground water $(\geq 200 \mathrm{ft})$. However, some locations where waste is stored in soil have much higher rainfal1, higher soil humus content, and short distances to groundwater. These conditions provide a situation in which enhanced mobility of nuclides via organics may be a dominant mechanism of nuclide transport. Furthermore, unanticipated changes in weather patterns or the water table may bring about increases in the mobility of nuclides. The discussions presented in this review are most applicable to water saturated soil systems or a worstcase unsaturated soil system where rainwater has reached the buried waste and is evaporating and condensing to the ground surface. This would lead to the upward mobility of water soluble material. 
TABLE 1. Four Selected Isotopes, Their Half-Lives, Decay Modes, Energies, and Principal Means of Production $(5,7)$

\begin{tabular}{|c|c|c|c|}
\hline ISOTOPE & HALF-LIFE & $\begin{array}{l}\text { DECAY MODES, } \\
\text { ENERGIES }\end{array}$ & $\begin{array}{l}\text { PRINCIPAL MEANS } \\
\text { OF PRODUCTION }\end{array}$ \\
\hline${ }^{93} \mathrm{ZR}$ & $1 \times 10^{6} y$ & $\beta-.063, .034$ & FISSION \\
\hline${ }^{63} \mathrm{Ni}$ & $92 y$ & $\beta-.067$ & $\mathrm{Ni}^{62}(n, \gamma)$ \\
\hline${ }^{99} \mathrm{TC}$ & $2.1 \times 10^{5} y$ & $\beta-.29$ & $\begin{array}{l}\text { FISSION } \\
M 0^{98}(n, \gamma), M^{99}(\beta-)\end{array}$ \\
\hline $93 m_{\mathrm{Nb}}$ & $13.6 y$ & IT e-(y) .029 & $\begin{array}{l}\text { FISSION } \\
\text { DAUGHTER OF Zr }\end{array}$ \\
\hline
\end{tabular}

TABLE 2. Classical Fractionation Scheme for Humus Matter of Soil(8)

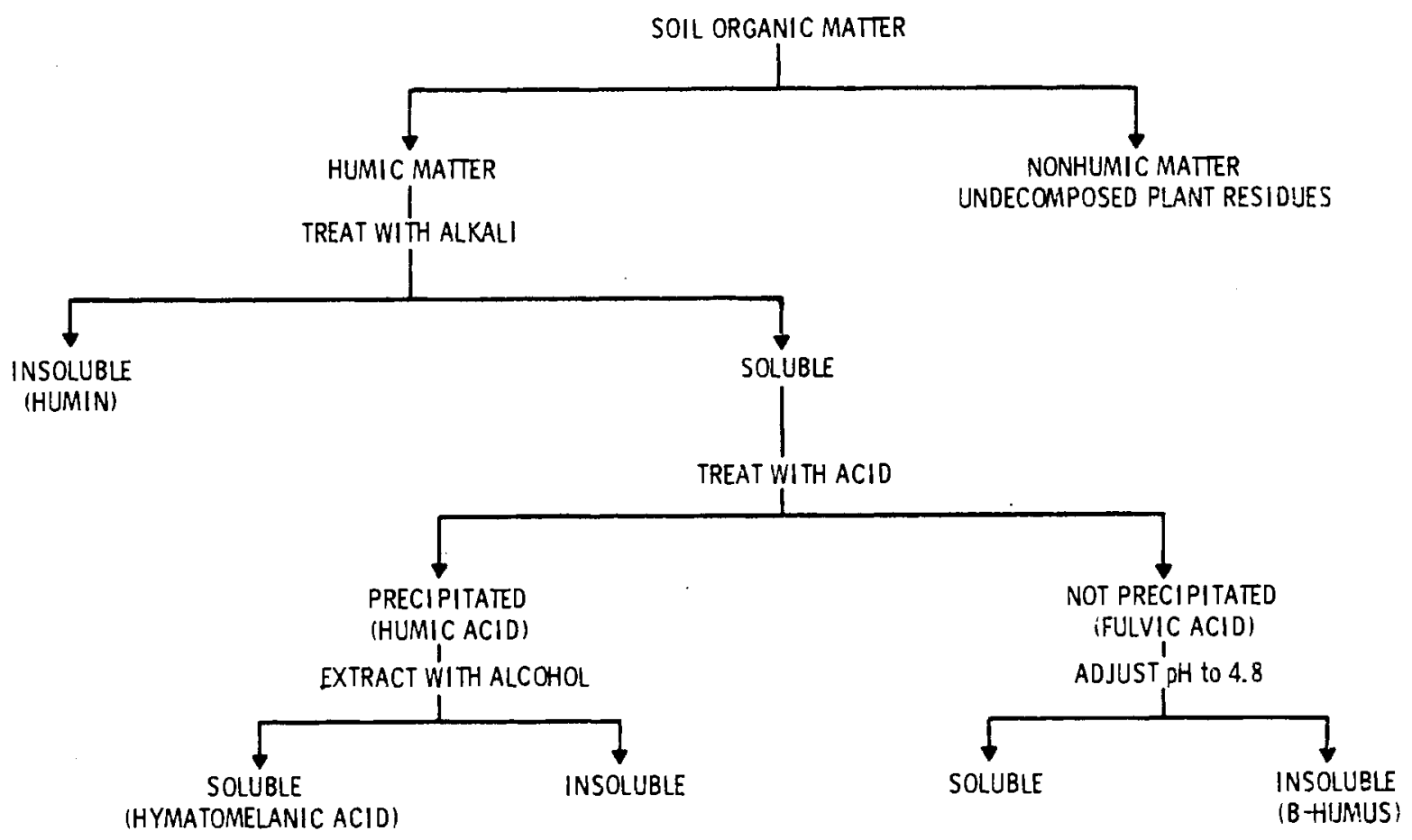


The mobile soil organic ligands, commonly referred to as humic acid, fulvic acids, and decomposing organic waste contain complex mixtures composed of oxygenated organic degradation products. The organic constituents of soils have been characterized in detail. $(9,10)$ soil organics are generally composed of amino acids, polysaccharides, polyfunctional aromatic compounds, and porphyrins. (7) The most abundant and we17-characterized fraction of soil, fulvic acid, is composed of a mixture of organic acids such as formic, acetic, benzoic, 3-hydroxy-5 methyl benzoic, p-hydroxy-benzoic, protocatechuic, vani1lic, gallic, propionic, citric, fumaric, malic, oxaloacetic, butyric, glycolic, lactic, and tartaric acids. $(9,11)$ These components are generally excellent biand polydentate chelating ligands for a variety of metals.

The waste derived organic ligands are determined by the type of waste which is buried. Chemicals which are commonly used at the Hanford Site in laboratory work, processing, and decontamination typify chemicals found in buried waste. These include polyphosphates ${ }^{(2)}$, mono, di-, and tributyl phosphate, aminepolycarboxylic ${ }^{(3)}$ acids such as ethylenediaminetetracetic acid (EDTA), diethylenetriaminepentaacetic acid (DTPA), nitrilotriacetic acid (NTA), and $\mathrm{N}$-hydroxyethylethylenediaminetriacetic acid (HEDTA), and carboxylic acids such as citric, hydroxy-acetic, oxalic, and tartaric acids.

The formation of coordination complexes of metals in solution by interaction with available organic ligands can be described by a cumulative equilibrium constant $\beta_{n}$. $\beta_{n}$ includes processes such as mono-, bi- or multidentate ligand coordination. The most kinetically stable ligands, typified by a structure common to humic material, ortho-hydroxybenzoic acid, are those which form chelating ligands. Interaction of a metal species (e.g., M)

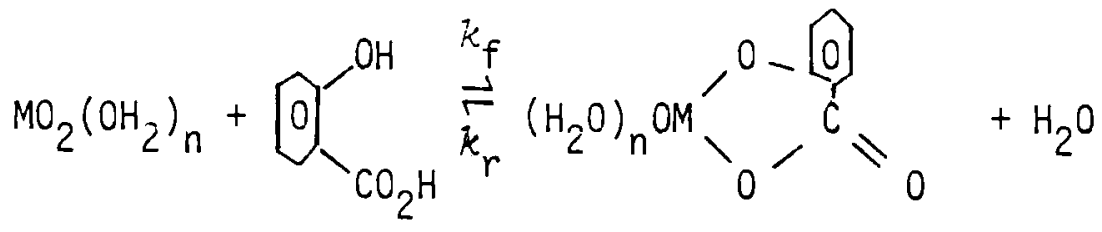

$$
\begin{aligned}
& \frac{k_{f}}{k_{r}}=k
\end{aligned}
$$


with one or more kinetically stable ligands results, for many metals, in the formation of soluble metal complexes which are often stable over broad $\mathrm{pH}$ ranges. In a series of such exchange reactions, the cumulative equilibrium constant $B_{n}$, or stability constant, is defined as follows:

$$
\begin{aligned}
& M+n L \underset{k_{r}}{\stackrel{k_{r}}{\leftrightarrows}} M L_{n} \\
& \beta_{n}=\frac{\left[M L_{n}\right]}{[M][L]^{n}} \prod_{i=1}^{n}
\end{aligned}
$$

The larger the stability constant is, the greater the extent to which the metal exists in complexed form. Note that equilibrium $k_{i}$ values are limited as a means of estimating the lifetimes of complexes due ordinarily to the lack of explicit rate constants, $k_{f}$ and $k_{r}$. Thus, dynamic soil chromatographic elution studies are often necessary to determine the effective kinetic stability constants. Furthermore, the above expression does. not account for the formation of multinuclear polymeric complexes and thus $k_{j}$ values for $\mathrm{Zr}$ and $\mathrm{Nb}$ in the literature are often of doubtful validity. Nevertheless, $k_{i}$ values serve as a qualitative indicator of complex lifetimes.

A variety of methods have been employed for determining the existence of complexed species in solution and their equilibrium constants. They include liquid-liquid partition (dis.), potentiometry (gl., H), polarography (pol.), amperometry (red.), ligand competition (kin.), solubility, ion exchange (ix.), freezing point, boiling point, vapor pressure, and spectrometry (sp.). Ionic strength and temperature can have large effects on this equilibirum value and the equilibrium can be complicated by polymeric and hydrolytic species in concentrated and non-acidic solutions. $(12,13)$

There are several routes to the formation of complexes from waste nuclide burial in soil. Complexes may be formed as a result of laboratory proceduras, process operation, or decontamination activities. A second route becomes available when metal species interact with buried, organic or soil-derived organic matter mobilized by water. 
The efficiency of complex formation depends on the amount of available water and organic material. In addition, it depends on the form of the metal. Thus, while fired zirconium oxide is virtually inert, hydrated zirconium oxide coprecipitated with other metal oxide hydrates may be kinetically labile to reaction with aqueous organic materials such as fulvic acids derived from soil humus matter.

When the metal and metal-organic complex species contact soil, mechanisms of interaction include ion exchange, precipitation, and mineral replacement. Two or more of these mechanisms can occur simultaneously. (5) The major variables in the soil environment which affect these interactions are temperature, $\mathrm{pH}$, clay content, organic carbon content, and cation exchange capacity of the soil. $(14,15,16)$ The minor variables in the soil environment which can also affect these interactions are competing cation content and presence of microorganisms. $\mathrm{Co}^{2+}$ and $\mathrm{Mg}^{2+}$ depress $\mathrm{Fe}$ complexation and stereospecific organic complexing can occur in micro-organisms.

The stability constant, $\beta_{n}$, provides a qualitative guide to the stability of organo-metal complexes, but provide little predictive ability for polynuclear complexes, mixed metal complexes, polymeric complexes and rates of complex formation. Thus, $\beta_{n}$ values based on cumulative equilibrium constants for simple synthetic solutions may fail to predict elution/stability characteristics in soil systems. (17)

Soil adsorption of nuclides may be approximated by $K_{d}$ values. $(5,18)$ The general formula is:

$$
K_{d}=\frac{A_{s}}{A_{w}} \times \frac{m l_{w}}{g_{s}} \quad \begin{aligned}
A s & =\begin{array}{l}
\text { amt of nuclide associated with } \\
\text { soil }
\end{array} \\
& A w-\text { amt of nuclide remaining in.. } \\
& \text { water } \\
& m l_{w}-\text { volume of water }(\mathrm{mls}) \\
g_{s} & - \text { weight of soil }(\mathrm{g})
\end{aligned}
$$


Two general experimental methods are used in determining $k_{d}$ values: column or batch. The column method employs a soil packed column. A water solution containing the nuclide to be studied is passed through the soil in the column at a constant flow and the effluent is monitored. The batch method involves the shaking of the nuclide solution and soil until equilibrium is attained. The supernatant is monitored. The column experiment washes away any water soluble soil ions which are retained in the batch experiment. The batch method could allow colloidal nuclide in the sampled supernatant whereas colloidal nuciide is potentially filtered out by the soil in the column experiment. $K_{d}$ values which are obtained from these experiments are subsequently used in computer models to predict the movement of the studied nuclides through water saturated soi1. $(19,20)$

The use of $k_{d}$ values in predicting the behavior of organically bound nuclides is in some ways more complicated than in predicting the behavior of inorganic nuclides. The organic molecule can bond very strongly with the nuclide to form a variety of charged and uncharged complexed species. Uncharged and anionically charged species should not be sorbed onto the anionically charged soil exchange sites. Even though other mechanisms may be involved in soil-nuclide interaction, the decrease in the cationic exchange mechanism will cause some organically bound nuclides to move rapidly through the soil. Since the $K_{d}$ value assumes a uniform absorption or nonabsorption behavior for a nuclide, unaltered $K_{d}$ values of organically bound nuclides having a non-facile equilibrium from which larger amounts of soil and/or nuclide can be extrapoiated, may not be valid. These problems can be circumvented by analyzing these variables and incorporating them into the $k_{d}$ value for each complex.

In the following sections the structures, stabilities, mechanisms of formation and soil elution behavior are discussed for complexes with structural features related to natural soil-derived complexing agents and synthetic chelating agents. Based on the available data in the literature, it wili be shown that synthetic organic complexing agents form stable, water soluble species with high potential mobility in soil systems. 


\section{ZIRCONIUM-ORGANIC COMPLEXES}

\section{AQUEOUS COMPLEX STABILITY}

It is well known that zirconium is found in aqueous solution only in the +4 oxidation state. (21) It has 8 or less coordination sites and has a great tendency to bond with ligands containing oxygen donor atoms. The aqueous chemistry of $\mathrm{Zr}$ is complicated by the formation of polymerized and hydrolyzed species of zirconium in solution. In solutions with $\mathrm{pH}$ greater than two, a colloidal polymerized precipitate of zirconium is formed. In highly acidic solutions the degree of polymerization of $\mathrm{Zr}$-species is reduced and $\mathrm{Zr}$ (IV) may exist in the cationic state, but more probably exists as hydrated zirconium. The structure has not been explicitly defined. Species existing at various $\mathrm{HCl}$ concentrations are depicted in Figure $1 .(6,22,23)$ Thus, most inorganic $\mathrm{Zr}$ complexes, with notable exceptions such as $\mathrm{ZrF}_{6}^{=}$, are instantiy hydrolyzed to polymer in soil media, and further transformations can be regarded as reactions of hydrous $\mathrm{ZrO}_{2}$ polymer or $\mathrm{MO}_{r} \cdot \mathrm{ZrO}_{2}\left(\mathrm{OH}_{2}\right)_{y}$ where $M$ is some other metal in the soil media. Once formed, further reaction depends on the ability of soluble organic or other species to dissolve these polymers.

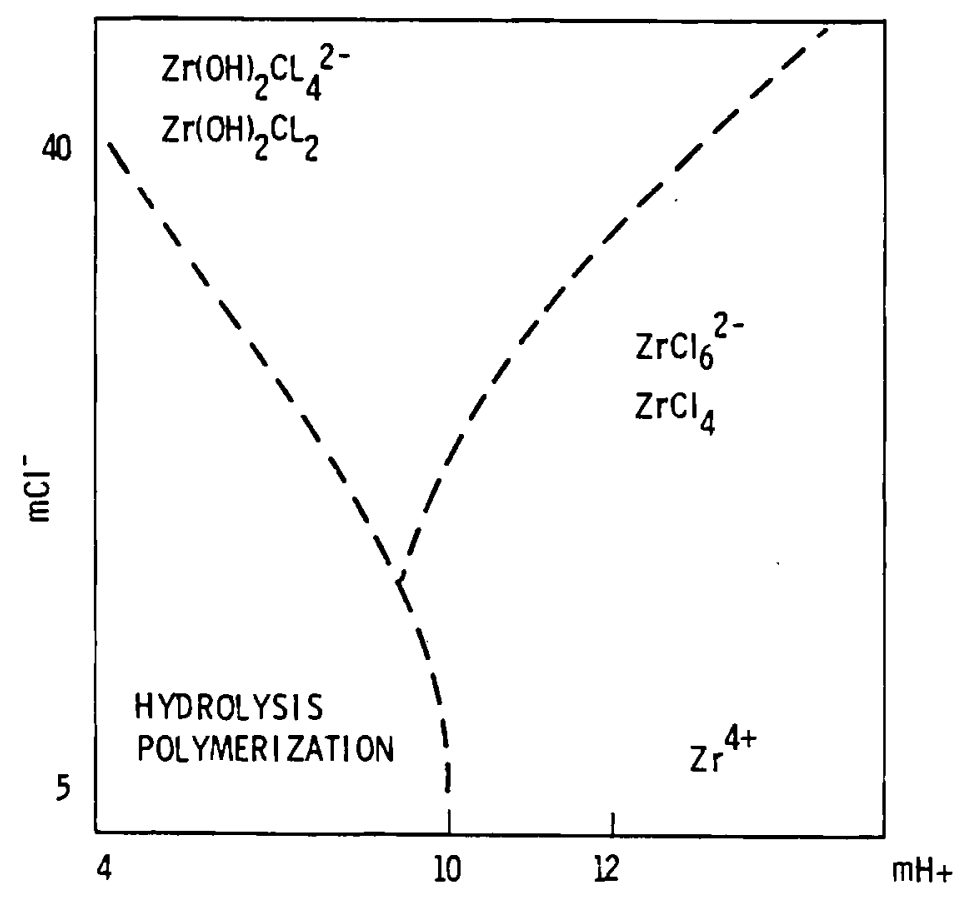

FIGURE 1. Zirconium in Aqueous Solution at Varying Concentrations and $\mathrm{pH}(\tilde{6}, 19,20)$ 
A great deal of research has dealt with the formation and stability of organic zirconium-complexes. Almost no work in soil media has been reported for organic $\mathrm{Zr}$ complexes. Because of the complexity of zirconium aqueous solutions, especially the tendency to form polymers, the study of zirconium complexes often has produced conflicting results due to the lack of reproducibility in the preparation of $\mathrm{Zr}^{4+}$ solutions. The equilibrium constants for interaction of a variety of organic ligands (presumably) with monomeric $\mathrm{Zr}^{4+}$ are listed in Table $3 .(12,13)$ It is apparent that zirconium-DTPA $\left(K_{1}=34-35\right)$ forms the most stable complex. Succinic, malic, lactic and gluconic acids form the least stable complexes with zirconium.

To determine the stability of such complexes in soil environments, studies at higher $\mathrm{pH}$ values are necessary. Intorre and Martell performed an exhaustive investigation of the stability and structure of zirconium complexes by potentiometric titration. (24) Ligands studied included bidentate ligands (e.g., tiron), quadridentate ligands, [nitrilotriacetic acid (NTA), hydroxyethyliminodiacetic acid (HIMDA), and $\mathrm{N}$-N-dihydroxyethylglycine (HXG)]; sexadentate ligands [EDTA, transcyclohexanediaminetetraacetic acid (CDTA), trimethylendediaminetetraacetic acid (TNTA), and $\mathrm{N}$-hydroxyethylenediaminetetracetic acid (HEDTA)]; septadentate ligands [oxybis-ethylenenitrilotetraacetic acid (OETA)]; and octadentate ligands [ethylenebis (oxyethylenenitrilo) tetraacetic acid (EOTA), and DTPA]. Complexes were formed by combining organic ligands with $\mathrm{Zr}^{4+}$ at low $\mathrm{pH}$. The potentiometric behavior over a pH range was examined. In some cases irreversible precipitation occurred after a given amount of sodium hydroxide had been added to the solution as for 1:1 Zr-EDTA at pH 8.0 when 3 moles of base/gm-ion $\mathrm{Zr}$ had been added. But precipitation did not occur for 1:2 Zr-HIMDA, Zr-HXG, or 1:1 Zr-tiron. Besides making specific conclusions on the structure of each complex (see Figure 2) at various $\mathrm{pHs,} \mathrm{it} \mathrm{is} \mathrm{generally} \mathrm{concluded} \mathrm{that} \mathrm{zirconium} \mathrm{forms} \mathrm{only}$ 5 -membered rings, has a maximum coordination number of 8 , and has the following coordinating tendencies:

$$
\mathrm{O}^{-2}>>\mathrm{OH}^{-}>\mathrm{RO}^{-}>\mathrm{RCOO}^{-}>\mathrm{R}-0-\mathrm{R}>\mathrm{N} \equiv \mathrm{R}_{3}
$$



TABLE 3. Stability Constants of Select Zirconium
Complexes in Aqueous Solution $(12,13)$

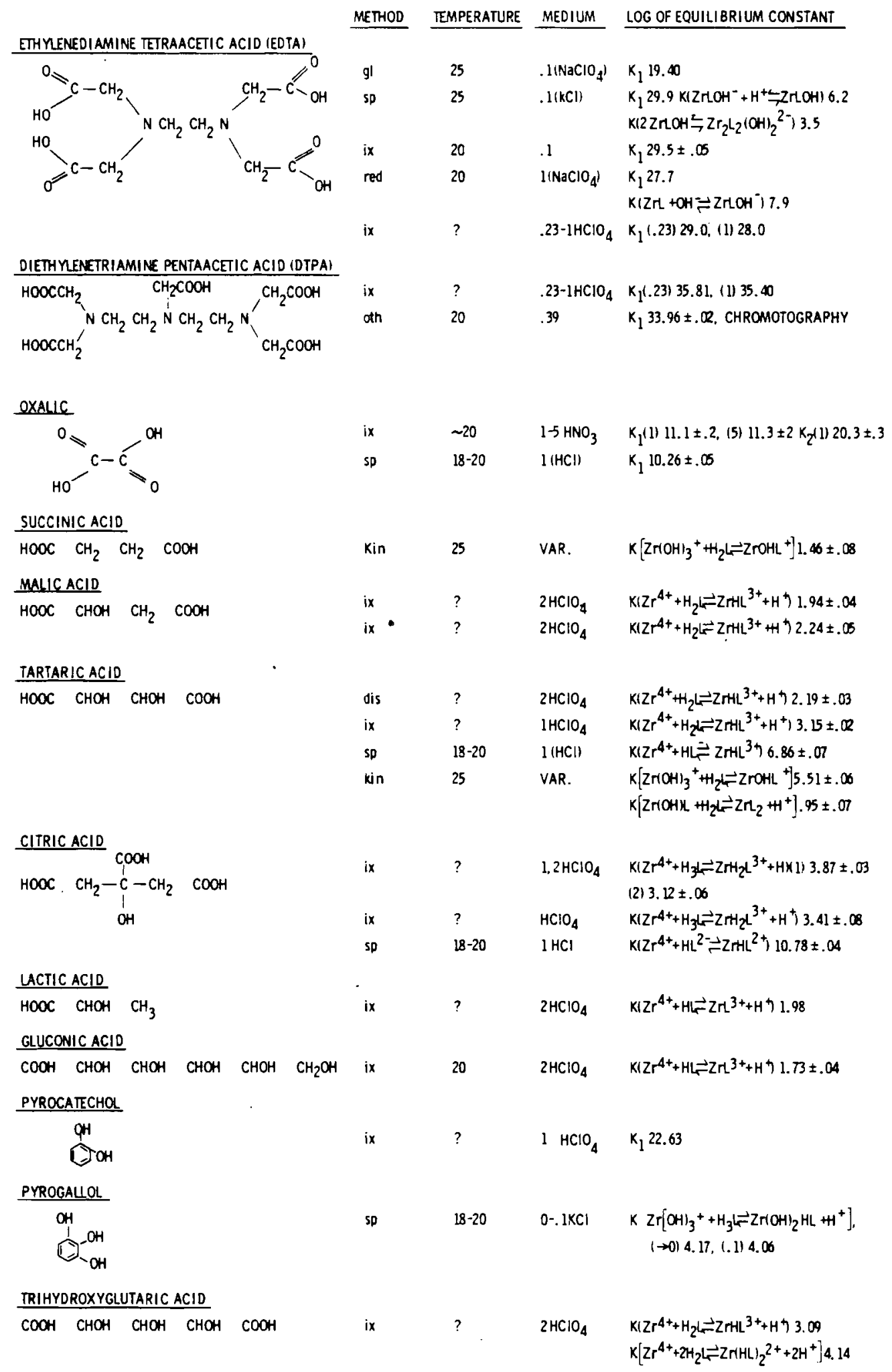




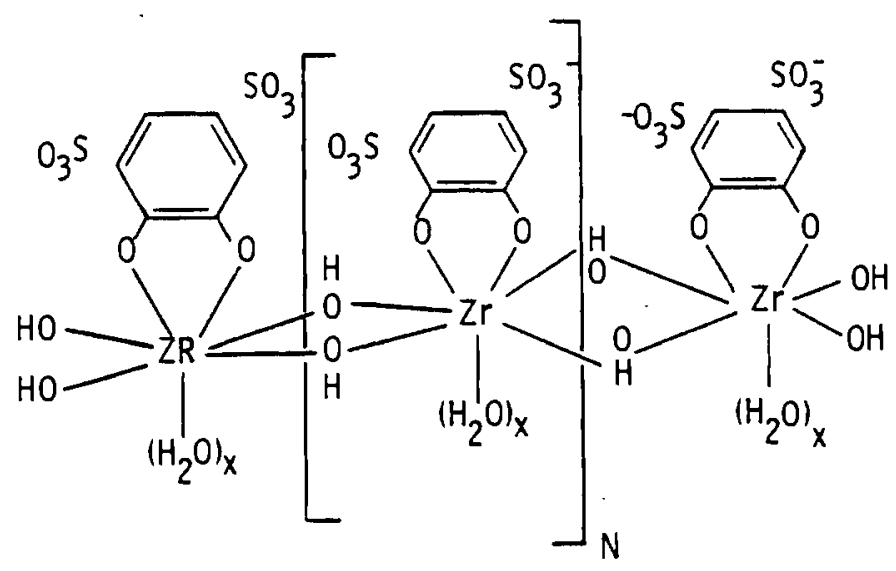

$\mathrm{Zr}-$ TIRON

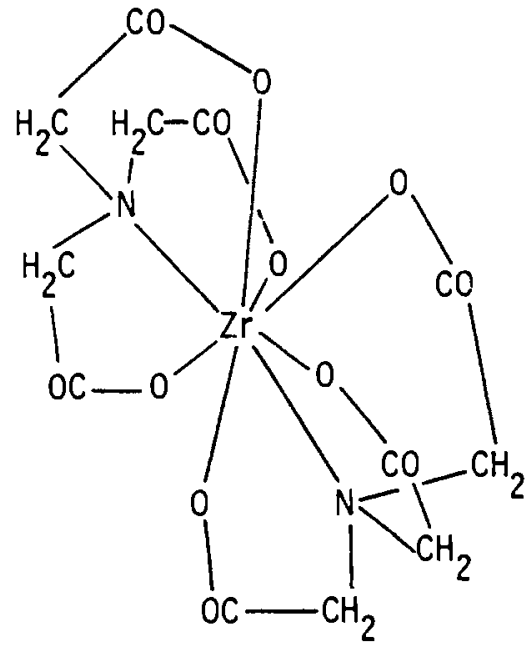

$\mathrm{Zr}-\mathrm{HIMOA}$

FIGURE 2. Probable Structure of Zr-Tiron Complex and $\mathrm{Zr}$-Himda Gomplex According to Intorre and Marte11 $(21)$

Ermakov, et al. (26) used ion exchange to study the stability of zirconium complexes. They concluded the following stability trend: oxalic > mesoxalic > tiron > trihydroxyglutaric > citric > lactic > tartaric > malic. (24) Ion exchange is a common method for studying metal organic complex stability but assumptions about the charge and structure of the resultant complexes are often arbitrary and erroneous.

Konunova, et al. (27) determined the charge, structure, and stability with electrophoresis, and photometric analysis over $\mathrm{pH}$ with an Arsenazo dye. They found two anionic complexes for each mixture at ratios of $1: 2$ and $1: 3$ (zirconium to ligand). They concluded the following stability trend which increases with additional complexant: trihydroxyglutaric > saccharic > mucic > tartaric > mesotartaric.

In an attempt to identify structures which form the most stable complexes, Ryabchikov, et al. (28) studied dicarboxylic acids with and without hydroxy groups. They determined that dicarboxylic acids without hydroxy groups show little tendency to complex. Dicarboxylic acids containing hydroxy groups 
sharply increase the tendency to complex. They identified the following stability trend: oxalic > mesooxalic > trihydroxyglutaric > citric > tartaric >lactic > malic. They proposed the following structure:

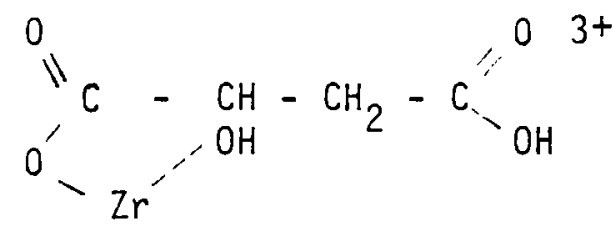

Korenman, et al., (29) determined that complex-forming tendency increases significantly where carboxylic acid and hydroxyl or keto-groups are in the alpha position by using an azo-dye and studying complexation photometrically. This tendency is less marked for aromatic carboyxlic acids; phthalic, salicylic, and gallic acid do not form complexes with zirconium in $1 \mathrm{~N} \mathrm{HCl}$ whereas mandelic and sulphosalicylic acids do form complexes. They established the following stability trend: NTA > acetylacetone > citric > oxalic > mandelic > tartaric > sulphosalicylic.

Overall stability of these structures over a range of pHs as would occur in natural water and soil systems is an important criterion for determining mobile complexation over a long time. Our studies show that most complexes (DTPA, EDTA, citric acid, HEDTA, formic acid and oxalic acid) precipitate at high pH, but tartaric acid, gluconic acid, protocatechuic acid and other acids composed of polyglycol structures form soluble complexes at high pH. It is clear from these studies that polyglycol or $\alpha$-hydroxy acid structures are essential for the stability and solubility of $\mathrm{Zr}$ complexes in highly alkaline sys tems.

Although the behavior of single ligand systems is fundamentally important, multiligand and multi-metal systems reveal more of the actual behavior of metals in natural waters and soils. Intorre and Martell performed the only experiments on zirconium-multi-ligand systems. (25) Their major conclusion in this study was that 1:1:1 Zr-EDTA-tartrate forms a nonprecipitable complex with potentiometric inflections that suggest the formation of a mixture of species or a polynuclear species. 
In summary, zirconium forms up to octacoordinate ${ }^{(24,25)}$ complexes in various five- and six-membered ring formations. $(27,28)$ Two functional groups in the organic ligand must meet one or more of the following conditions for the stable chelate formation:

- primary acid group in which metal ion replaces acid hydrogen

- neutral group containing an atom with non-bonding electrons. Functional groups which satisfy these criteria in order of bonding strength are:

$$
\mathrm{O}^{-2}>>\mathrm{OH}^{-}>\mathrm{RO}^{-}>\mathrm{RCOO}^{-}>\mathrm{R}-\mathrm{O}-\mathrm{R}>\mathrm{R}_{3} \equiv \mathrm{N}
$$

The stability of the complex increases sharply when the second group (carboxyl, hydroxy 1 , keto) is in the alpha position. (29) Thus, multidentate compiexing ligands such as EDTA, and DTPA form the most stable complexes because one ligand molecule can fill most of zirconium's coordination sites without steric hindrance. If the $\mathrm{pH}$ of the system exceeds $\mathrm{pH} \mathrm{8.0,} \mathrm{however,} \mathrm{water} \mathrm{insoluble} \mathrm{species} \mathrm{are}$ formed. Multidentate ligands like HIMDA, HXG, and tiron also form highly stable complexes filling most of the available coordination sites but, insoluble species are not formed at high pH. Although hydroxy acids with more than one hydroxyl group (especially alpha to a carboxyl group) are not as stable, they are not destroyed or precipitated by high pH, either alone or in any one of the above systems.

\section{AQUEOUS COMPLEX STABILITY IN SOIL SYSTEMS}

Uncomplexed zirconium is readily taken up by Hanford soil as can be seen in Figure 3. ${ }^{(5)}$ Absorption from a $\mathrm{Zr}-\mathrm{HCl}$ solution is less below pH 2 and between 8 and 10. This absorption is not affected by the presence of other cations except at $\mathrm{pH}<2.0$.

Various investigators have hypothesized that soil uptake of zirconium would be adversely affected by organic ligands which could complex with zirconium to form uncharged or anionic species, $(5,17)$ but no actual data is available. Therefore, one can only predict complex behavior in soil from aqueous zirconiumligand stability, structure, solubility, and charge. 


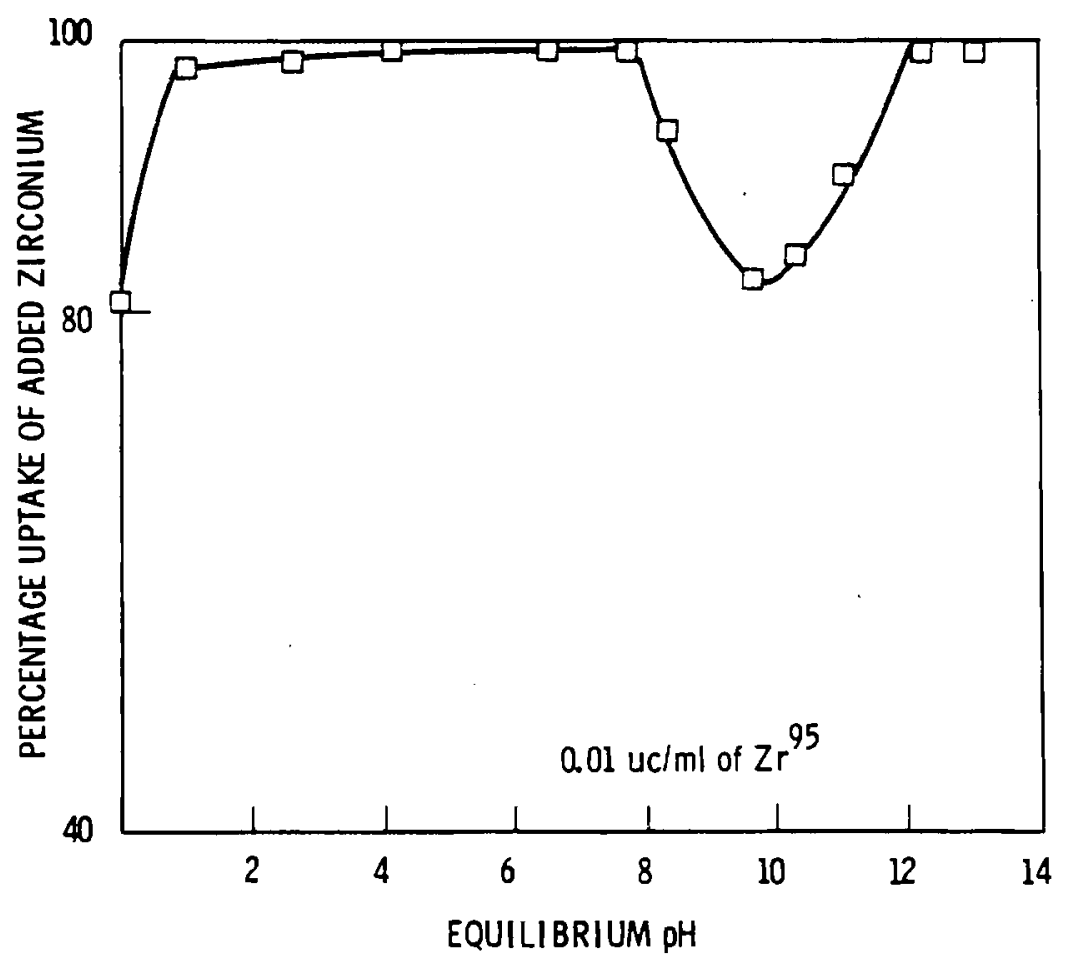

FIGURE 3.. Zirconium Uptake by Calcareous Hanford Soils (5)

At first approximation, one could directly use the stability constants in Table 2, and predict that $\mathrm{Zr}$-EDTA and $\mathrm{Zr}$-DTPA would form the most stable complexes. But as has been discussed, available stability constants have been determined only at low pH values. Very few stability constants have been determined at $\mathrm{pH}>2$.

Both of these complexes also would be unstable in highly alkaline soils. (24) Stability constants also do not indicate the solubility of the complex in water. Oxalic acid and acetylacetone are stable and soluble in acidic water but they are sparingly soluble in neutral water. $(12,13,24,28,29,30)$ One would predict from Table 2 that carboxylic acids like succinic acid would complex with zirconium to a limited extent but monodentate complexation becomes negligible in very dilute solutions. The overall consensus after considering these limitations, is that excess HIMDA, HXG, tiron, or mixtures or EDTA and tartaric acid (or other polyglycol structures) form extremely water soluble, stable 
complexes. Whether these complexes are absorbed by soil, though, cannot be predicted a priori. The charge on these complexes is assumed in most cases and has not been proven.

In conclusion, waste derived complexing ligands having structures similar to HIMDA, HXG, or mixtures of EDTA and tartaric acid appear to complex with zirconium to form the most soluble complexes. Compounds which reportedly have similar structures to soil organics like quinoline-2-carboxylic acid, and salicylic acid from unstable complexes. $(10,31)$ Thus, the structural features of $\alpha$-hydroxy carboxylic acids that lead to highly stable complexes are not entirely clear. But the stabilities of mixed complexes and complexes with polyfunctional agents such as soil fulvic acid can not be predicted a priori and thus may still exhibit wide variations in stability.

Future work must clarify the role of complexing agents in mobilizing zirconium. This would involve studies in which organic ligands and $\mathrm{Zr}$ interact at neutral and slightly higher $\mathrm{pH}$. The role of polymerization and hydrolysis in affecting compound structure, stability, and complex charge needs to be defined as well as the resultant absorption properties of poiymeric species by soil. The effects of unstudied multi-ligand, multi-metal systems particularly of niobium, a zirconium daughter fission product, on complex formation and resultant soil absorption would also need to be defined. Finally, the mechanism of precipitate solubilization and soil mineral replacement should be studied. As yet, no study has considered the solubilization of hydrous $\mathrm{ZrO}_{2}$ by organic complexing agents or by humic or fulvic acids. 


\section{NIOBIUM ORGANIC COMPLEXES}

AQUEOUS COMPLEX STABILITY

Niobium is found in aqueous solution entirely in the +5 oxidation state. ${ }^{(22,32)}$ At $\mathrm{pH}<7 \mathrm{Nb}$ forms insoluble polymeric hydrous oxides. (33) this pH range, niobium is soluble only as a complex ion. (33) In solutions $\mathrm{pH}>7$, niobium has a reduced tendency to form polymers. Niobium has a great affinity for oxygen donor ligands. The preparation of $\mathrm{Nb}(\mathrm{V})$ solutions poses difficulties of reproducibility reminiscent of $\mathrm{Zr}$. The aqueous complex chemistry of $\mathrm{Nb}$ has received less attention than that of zirconium. Table 4 lists some representative stability constants. EDTA and protocatechuic acid appear to form the most stable complexes whereas hydroxy-acids have the lowest stabilities.

Fairbrother, et al., performed early work in characterizing niobium complex formation. They determined that five member ring complexes tend to be the most stable, ${ }^{(34)}$ especially when formed with an alpha-hydroxy acid. Niobium bonds either with two hydroxyl groups or one hydroxyl and one carboxyl group. $\mathrm{Nb} \alpha$-hydroxy complexes hydrolyze with reformation of the reactants unless in the presence of at least 3 -fold or more of the ligand. The resultant complex is destroyed by either mineral acids or strong alkali (glycollic, lactic, malic, citric). (35)

Qureshi, et al.., (36) determined the resultant charges of niobium-complex solutions. A niobium solution of 2 percent tartaric acid results in a complex with a positive charge. Whereas a niobium solution of 10 percent tartaric acid or 10 percent formic acid results in a negatively charged complex.

Several complexes of niobium which possess two different complexing ligands are known. (32) They include:

- a hydroxy acid and an organic base (polyhydric-phenol or EDTA)

- salicylic acid and an organic base

- oxalate ions and pyrogal101

- EDTA and pyrogal1ol

Stability constants were not determined for these systems. 
TABLE 4. Stability Constants of Select Niobium Complexes

\begin{tabular}{|c|c|c|c|c|}
\hline & METHOD & TEMPERATURE & MEDIUM & LOG OF EQUILIBRIUM CONSTANT \\
\hline EDTA & pol & 20 & 1 & 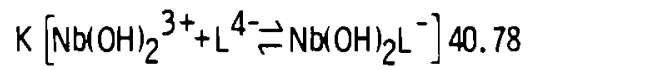 \\
\hline \multirow[t]{2}{*}{ OXALIC ACID } & dis & 20 & $\begin{array}{l}4.5(\mathrm{NaCl} \text { or } \\
\mathrm{NaNO}_{3}+2.5 \\
\mathrm{HCl})\end{array}$ & $\begin{array}{l}\left.\mathrm{K}\left[\mathrm{Nb}(\mathrm{OH})_{4}{ }^{+}+\mathrm{H}_{2} \mathrm{~L}^{-} \rightleftharpoons \mathrm{\sim} \mathrm{Nb(OH}\right)_{2} \mathrm{~L}_{2}^{-}\right] 3.55 \\
\mathrm{~K}\left[\mathrm{Nb}(\mathrm{OH})_{4}^{+}+2 \mathrm{H}_{2} \mathrm{~L}=\mathrm{Nb}(\mathrm{OH})_{2} \mathrm{~L}_{2}^{-}+2 \mathrm{H}^{+}\right] 5.13\end{array}$ \\
\hline & $\mathrm{pH}$ & 25 & 0.5 & $\begin{array}{l}\mathrm{K}\left[\mathrm{Nb}(\mathrm{OH})_{4}{ }^{+}+2 \mathrm{HL}^{-}-\mathrm{Nb}(\mathrm{OH})_{2} \mathrm{~L}^{-}\right] 12.11 \\
\mathrm{~K}\left[\mathrm{Nb}(\mathrm{OH})_{4}{ }^{+}+2 \mathrm{HL}^{-}+\mathrm{L}^{2-}-\mathrm{NblOH}_{2} \mathrm{~L}_{3}{ }^{3-}\right] 17.15\end{array}$ \\
\hline SUCCINIC ACID & dis & 20 & $\begin{array}{l}4.5\left(\mathrm{NaCL}_{\text {or }}\right. \\
\mathrm{NANO}_{3}+2.5 \\
\mathrm{HCl})\end{array}$ & $\mathrm{K}\left[\mathrm{Nb}(\mathrm{OH})_{4}^{+}+\mathrm{H}_{2} \mathrm{~L} \overrightarrow{\mathrm{N}} \mathrm{Nb}(\mathrm{OH})_{4} \mathrm{HL}+\mathrm{H}^{+}\right] 1.53$ \\
\hline MALIC ACID & & & & K 2.01 \\
\hline CITRIC ACID & & & & K 2.94 \\
\hline TARTARIC ACID & & & & K 2.34 \\
\hline PROTOCATECHUIC ACID & & & & 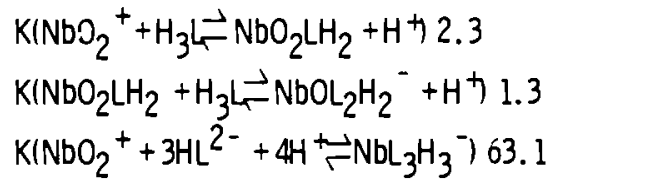 \\
\hline METHANOL & $H$ & 20 & $\begin{array}{l}\text { I }\left(\mathrm{CH}_{3}\right)_{4} \mathrm{NCl} \\
\text { METHANOL }\end{array}$ & $K_{.15} 10.45 \quad K_{6} 5.45$ \\
\hline ACETYLACETONE (HA) & & & & $\begin{array}{l}\left.\mathrm{KINDL}_{4}{ }^{+}+\mathrm{A}^{-} \vec{\sim} \mathrm{NbAL}_{4}\right) 10.84 \\
\left.\mathrm{KINDAL}_{3}{ }^{+}+\mathrm{L}^{-} \vec{\sim}-\mathrm{NbAL}_{4}\right) 12.4 \\
\left.\mathrm{KINbL}_{5}+\mathrm{HA}^{-}=\mathrm{NbAL}_{4}\right) 5.18\end{array}$ \\
\hline CATECHOL $\left(\mathrm{H}_{2} \mathrm{~B}\right)$ & & & & 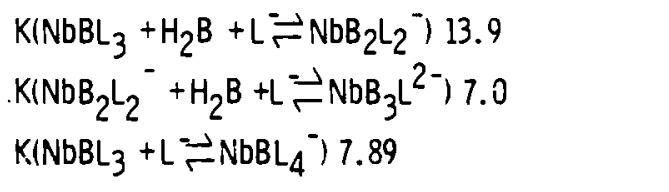 \\
\hline SALICYLIC ACID & sp & 25 & 0.04 & 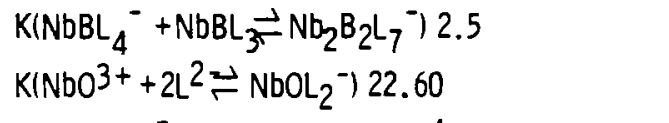 \\
\hline GLUCONIC ACID & اg & 25 & 0.1 & 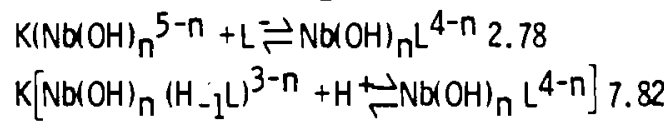 \\
\hline
\end{tabular}




\section{AQUEOUS COMPLEX STABILITY IN SOIL SYSTEMS}

$\mathrm{Nb}$ exhibits properties reminiscent of $\mathrm{Zr}$ in aqueous media. To date, there are no data on the movement of inorganic or organic ${ }^{95}$ niobium through soil. From the tendency of niobium to form insoluble oxygen-bridged polymers in aqueous media and of organically complexed niobium to hydrolyze one would predict that all niobium would be efficiently absorbed by soil. Nb appears to undergo exchange of oxygen ligands more readily than $\mathrm{Zr}$. This results in a lower predicted lifetime of soluble organic complexes of $\mathrm{Nb}$ and hence the more efficient formation of hydrous niobium oxide and its consequential absorption by soil.

Future work with niobium complex ligand chemistry should involve its role in $\mathrm{Zr}$-Nb mixed-complex formation. The stability and water solubility of mixedmetal-mixed-ligand complexes should be examined. The effects of multiple cationic and anionic species on this complex formation, stability, and solubility should be further explored. 


\section{NICKEL-ORGANIC COMPLEXES}

\section{AQUEOUS COMPLEX STABILITY}

Nickel is found in aqueous solution only in the +2 oxidation state. The coordination numbers and geometries of various nickel organic complexes is very extensive and beyond the scope of this paper. ${ }^{(22)} \mathrm{Nickel}$ is highly soluble in water when the $\mathrm{pH}>6.7$. (37)

Numerous investigators have studied the complex formation and stability of nickel organic complexes. Table 5 lists some select stability constants obtained by various investigators. Nickel-DTPA and nickel-EDTA are among the most stable complexes. Nickel succinate and nickel lactate are among the least stable complexes. (38)

In an attempt to ascertain the relative stability of hydroxy acid complexes of nickel at $\mathrm{pH} 6.0$, one investigator found that anionic complexes were formed according to the following order of stability: citric > glutaric > tartaric $>$ malic.

Nickel complexation and the charge of the resultant complex is $\mathrm{pH}$ dependent. Several investigators determined that nickel-gluconate is very stable at high $\mathrm{pH}$ whereas it is significantly less stable at $\mathrm{pH}>7.0$. They claimed that positively charged complexes as well as negatively charged complexes exist between $\mathrm{pH} 4.5$ and 7.5 whereas only positively charged complexes exist at $\mathrm{pH}>4.5 .^{(40)}$ Another investigator ${ }^{(47)}$ determined that insoluble species are formed between $\mathrm{pH} 7$ and $\mathrm{pH} 9$ having the structure $\mathrm{N}_{2}\left(\mathrm{C}_{6} \mathrm{H}_{17} \mathrm{O}_{7}\right)(\mathrm{OH})_{3} \mathrm{H}_{2} \mathrm{O}$ or $\mathrm{Ni}_{2}\left(\mathrm{C}_{6} \mathrm{H}_{10} \mathrm{O}_{7}\right) \mathrm{OH}_{2} 2 \mathrm{H}_{2} \mathrm{O}$. At $\mathrm{pH}$ greater than 9, a soluble anionic species is formed in the ratio $1: 2(\mathrm{Ni}: \mathrm{OH})$ having the structure $\mathrm{Ni}_{2}(\mathrm{OH})_{4}\left(\mathrm{C}_{6} \mathrm{H}_{70} \mathrm{O}_{7}\right)^{-}$. $\mathrm{Ni}$-tartrate or -citrate form anionic complexes in the ratio $1: 1$ at $\mathrm{pH}$ greater than $7 .(42)$

Although $\mathrm{Ni}(\mathrm{OH})_{2}$ does not readily precipitate below $\mathrm{pH} 6.7$, the role of complexes in preventing nickel precipitations is still great. Our studies indicate that Ni-EDTA, -DTPA, -HEDTA, -gluconate, -tartrate do not precipitate above pH 6.7. 
TABLE 5. Stability Constants of Select Nickel Complexes in Aqueous Solution $(12,13)$

\begin{tabular}{|c|c|c|c|c|}
\hline & METHOD & TEMPERATURE & MEDIUM & LOG OF EQUILIBRIUM CONSTANT \\
\hline \multirow[t]{3}{*}{ ETH YLENEDI AMINETETRAACETIC ACID (EDTA) } & Sp & 30 & $0.1\left(\mathrm{KNO}_{3}\right)$ & $\mathrm{K}_{1} 17.5$ \\
\hline & pol & 20 & $0.1\left(\mathrm{KNO}_{3}\right)$ & 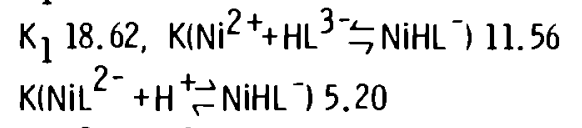 \\
\hline & Sp & -- & $\mathrm{l}\left(\mathrm{NaClO}_{4}\right)$ & 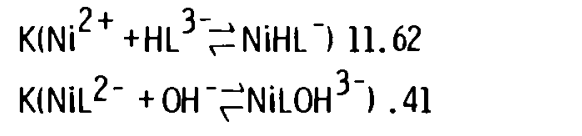 \\
\hline DIETHYLENETRIAMINEPENTAACETIC ACID (DTPA) & $g l$ & 25 & $0.1\left(\mathrm{KNO}_{3}\right)$ & $K_{1} 20.2, K_{2} 5.59$ \\
\hline (HEDTA) & $g l$ & 29.6 & $0 . \mathrm{l}(\mathrm{KCl})$ & $K, 17.0$ \\
\hline NITRILOTRIACETIC ACID (NTA) & dis & 20 & $0.1\left(\mathrm{KClO}_{4}\right)$ & $\mathrm{K}_{\mathrm{l}} 11.54 \pm 0.08$ \\
\hline OXALIC ACID & $g l$ & 25 & 0.1 & $\mathrm{~K}_{1} 5.3$ \\
\hline SUCCINIC ACID & $g l$ & 25 & 0.1 & $K_{l} 1.6$ \\
\hline LACTIC ACID & oth & 25 & 0.20 & $\mathrm{~B}_{2} 1.89$ CIRCULAR DICHROISM \\
\hline CITRIC ACID & $g l$ & 20 & $0.1\left(\mathrm{NaClO}_{4}\right)$ & $K_{1} 5.40$ \\
\hline MALIC ACID & $g !$ & 20 & $0.1\left(\mathrm{NaClO}_{4}\right)$ & 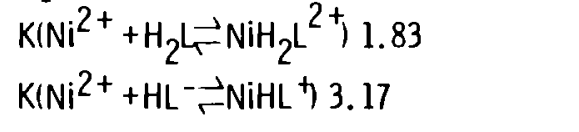 \\
\hline TARTARIC ACID & dis & 20 & $0.1\left(\mathrm{KClO}_{4}\right)$ & $\beta_{2} 5.42 \pm .06$ \\
\hline \multirow[t]{2}{*}{ GLUCONIC ACID } & $g l$ & 25 & $0.12\left(\mathrm{KNO}_{3}\right)$ & $\begin{array}{c}\mathrm{K}\left[2 \mathrm{Ni}^{2+}+4 \mathrm{OH}^{-}+\mathrm{L}^{-}-\vec{\Gamma} \mathrm{Ni}_{2}(\mathrm{OH}){ }_{4} \mathrm{~L}^{-}\right] 29.4 \\
\mathrm{pH}>9(? ?)\end{array}$ \\
\hline & Sp & 25 & $0.12\left(\mathrm{KNO}_{3}\right)$ & $\begin{array}{l}\mathrm{K}_{1} 1.82, \mathrm{pH}<7(?) \\
\mathrm{K}_{5}\left[\mathrm{Ni}_{2}(\mathrm{OH})_{3} \mathrm{~L}\right]-27, \mathrm{pH} 7-9\end{array}$ \\
\hline SALICYLIC ACID & $g l$ & 25 & $\begin{array}{l}0.1 \mathrm{NaClO}_{4} \\
75 \% \text { DIOXAN }\end{array}$ & $K_{1} 8.41, K_{2} 7.04$ \\
\hline QUINOLINE-2-CARBOXYLIC ACID & $g$ & 25 & $\begin{array}{l}\sim 0.01,50 \% \\
\text { DIOXAN }\end{array}$ & $\begin{array}{l}\mathrm{K}_{1} 3.5, \mathrm{~K}_{2} 2.7 \\
\mathrm{~K}\left(\mathrm{NiOHL}{ }^{-}+\mathrm{H}^{+} \overrightarrow{\ulcorner} \mathrm{NiL}\right) 7.2 \\
\mathrm{~K}\left[\mathrm{Ni}(\mathrm{OH})_{2} \mathrm{~L}^{2-}+\mathrm{H}^{+} \vec{\sim} \mathrm{NiOHL}-9.5\right]\end{array}$ \\
\hline
\end{tabular}


A significant amount of work has addressed the stability of mixed ligandmixed metal complexes of nickel. Table 6 lists select stability constants of some mixed ligand-mixed metal complexes. Some mixed ligand complexes are more stable than single ligand complexes ( $\mathrm{Ni}$-EDTA-glycine is more stable than $\mathrm{Ni}$-EDTA) and some mixed metal-mixed ligand complexes are more stable than mixed ligand complexes (Ni-Co-EDTA-glycine is more stable than Ni-EDTA-glycine).

TABLE 6. Stability Constants of Mixed Ligand Mixed Metal Ni Complexes

\begin{tabular}{|c|c|c|c|c|}
\hline & METHOD & IEMPERATURE & MEDIUM & LOG OF EQUILIBRIUM \\
\hline NITRILOTRIACETIC ACID (NTA) & $g^{13}$ & $?$ & $0.5\left(\mathrm{NaNO}_{3}\right)$ & \\
\hline SALICYCLIC ACID $\left(\mathrm{H}_{2} A\right)$ & & & & KINiL $\left.{ }^{-}+A^{2} \rightleftharpoons N i L A^{3-}\right) 3.0 R$ \\
\hline GLYCINE (HA) & & & & $K\left(\mathrm{NiL}^{-}+\mathrm{A} \underset{\sim}{\sim} \mathrm{NiLA}^{2-}\right) 4.41$ \\
\hline PYRIDINE ALDOXIME (A) & & & & 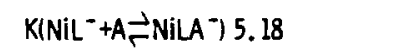 \\
\hline $\mathrm{NH}_{3}(\mathrm{~A})$ & $S p l 3$ & 25 & $0.5(\mathrm{KC}))$ & $\left.\mathrm{KiNiL}^{-}+\mathrm{A}_{\rightleftharpoons} \rightleftharpoons \mathrm{NiLA}{ }^{-}\right) 2.54$ \\
\hline ETHYENEDIAMINE & & & $0.5\left(\mathrm{NaClO}_{4}\right)$ & 7.20 \\
\hline GLYCINE & & & $0.5(\mathrm{NaCl})$ & $\left.\mathrm{KINiL}^{-}+\mathrm{A}^{-} \rightleftharpoons \mathrm{NiLA}^{2-}\right) 4.89$ \\
\hline OXALIC & & & $0.5\left(\mathrm{KNO}_{3}\right)$ & KINiL $\left.{ }^{-}+A^{2-} \rightarrow N_{N i L A}^{3-}\right) 2.17$ \\
\hline ETHYVALINATE & gl13 & 25 & $0.07-.08$ & KINIL"+A-ANiLA 12.03 \\
\hline ETHYLENED IAMINETETRACETIC ACID & $S_{p} 13$ & 25 & 1. $\left.\mathrm{ONaClO}_{4}\right)$ & $\left.\mathrm{KiNiL}^{2-}+\mathrm{A} \rightleftharpoons \mathrm{NiLA}{ }^{2-}\right)$ \\
\hline HYDROXYLAMINE (A) & & & & K 1.5 \\
\hline HYDRAZINE (A) & & & & $K 1.66$ \\
\hline PYRIDINE (A) & & & & K 1.69 \\
\hline ETHYLNEDIAMINE (A) & & & & $\mathrm{K} 2.3$ \\
\hline PROPYIENEDIAMINE (A) & & & & $K 2.3$ \\
\hline & $\mathrm{sp}^{36}$ & 25 & 1.5 & $\mathrm{NiL}+\mathrm{A}_{\overrightarrow{\mathrm{N}} \mathrm{NiLA}}$ \\
\hline GLYCINE (A) & & & . & 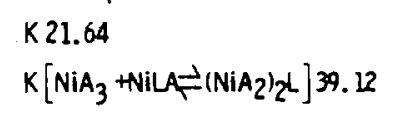 \\
\hline OXALATE (A) & & & & $\begin{array}{l}\mathrm{K} 20.01 \\
\mathrm{~K}\left[\mathrm{NiA}_{3}+\mathrm{NiLA}-\left(\mathrm{NiA}_{2} \mathrm{~K}_{2} \mathrm{~L}\right] 32.03\right.\end{array}$ \\
\hline MANGANESE ETHYENDIAMINE & $S p 41$ & 25 & 1.5 & B 34.40 . \\
\hline COBALT ETHYLENEDIAMINE & & & & B 41.75 \\
\hline COBALT GLYCINE & & & & B 36.66 \\
\hline COBALT OXALATE & & & & $\beta 32.02$ \\
\hline COPPER ETHYLENED IAMINE & & & & B 44.48 \\
\hline COPPER GLYCINE & & & & B 38.84 \\
\hline COPPER OXALATE & & & & B 31.73 \\
\hline
\end{tabular}


Barkhanova, et el., (32) found spectrophotometrically that Ni-EDTA-oxalate and. Ni-EDTA-glycine form extremely stable complexes. Their general formula is $\operatorname{MEDTAX}\left(\mathrm{MX}_{2}\right)_{2} \operatorname{EDTA}(M-n i c k e 1, X$-oxal ic acid or glycine). The regularity of this stability is the same for dinuclear mixed compounds and mononuclear mixed compounds.

Barkhanova, et al., (43) also found that mixed metal-mixed ligand complexes are more stable than simple mixed-ligand complexes. They determined the stability constants spectrophotometrically and claimed that the structures ( $\mathrm{NiX}_{2}$ ) EDTA $\left(\mathrm{CoX}_{2}\right)$ or $\left(\mathrm{MnX}_{2}\right)$ EDTA $\left(\mathrm{NiX}_{2}\right)$ were formed. The coordination spheres of the dissimilar metals in each of these molecules have a similar octahedral structure. Other complexes were found having the following structure, e.g., $\left(\mathrm{NiX}_{2}\right)$ EDTA (CUX). The dissimilar metals in these molecules have coordination polyhedra of different form.

In summary, nickel salts combine with ammonia or nitrogen containing compounds to form water soluble compounds even at high $\mathrm{pH}$. Nickel also bonds with nitrogen and oxygen containing compounds to form five or six membered organic chelates. This bonding results in an inner complex salt in which metal ion replaces a hydrogen ion and is coordinatively bound at some other point that functions as the acidic radical. (37) The kind and number of uncomplexed functional groups and the degree of ligand linking between metallic ions determines the water solubility of the resultant complex. (32) Alphahydroxy carboxylic acids form the more stable carboxylate complexes with nickel.

Thus, over a broad range of $\mathrm{pH}$, nickel is soluble and stable in aqueous solution with or without organic ligands, but because of its charge in the uncomplexed state, it can be absorbed by soil. Organic ligands tend to accelerate $\mathrm{Ni}$ transport.

\section{AQUEOUS COMPLEX STABILITY IN SOIL SYSTEMS}

Several investigators have studied the movement through soil of complexed nickel or cobalt, which is chemically similar. Chebotina found that plant extracts (pine needles, linden and aspen leaves) increase the movement of 
cobalt through soil. (44) cobalt movement through soil is increased also by bonding with EDTA and DTPA. (45) DTPA and NTA increase the concentration of nickel which moves through soil and into the leaves of a bush bean plant.

Nickel and cobalt can be removed by complexing organics after their absorption by soil. Chebotina found that leaf extracts will desorb cobalt from soil. (47) cobalt can also be desorbed from soil by the following acids and organics in order of decreasing desorption: 10 percent HCI > EDTA > EDTA $>0.1 \mathrm{M} \mathrm{HCl}$, plant extracts, $\mathrm{CH}_{3} \mathrm{COOH}$ and dithizone $>\mathrm{CH}_{3} \mathrm{COOH}>\mathrm{HNO}_{3}$.

The interaction of soil organics with nickel is the subject of current research. Schnitzer claims that fulvic acid (FA) interacts in two distinct fashions with nickel: one appears to involve the formation of a complex incorporating both a carboxylic function and phenolic $\mathrm{OH}$ and a second category of complex involves only a weakly acidic carboxylic function. The complex involving both carboxylate and phenolic $\mathrm{OH}$ in the FA material is more effective in preventing the absorption of $\mathrm{Ni}$ by fixed soil constituents. (49) In Table 7 are listed stability constants of nickel-fulvic acid complexes. Schnitzer $(50)$ and Mantoura (51) found that these stability constants were not extremely high, compared to stability constants of some ligands (Table 7). The nickel-fulvic acid stability constants are less than a model compound for mobile soil components, salicylic acid, but more than another soil model, quinoline-2-carboxylic acid.

One would predict, therefore, that a wide variety of organic ligands would solubilize nickel in soil. EDTA, DTPA, HEDTA and NTA are specially effective in mobilizing $\mathrm{Ni}$. More work is necessary to determine the effect of organic chelating liquids in the low humus content Hanford soil system and the mechanism of solubilization of nickel precipitates or nickei coprecipitated with inorganic soil constituents. The low fulvic acid content of Hanford soil is expected to minimize this mode of $\mathrm{Ni}$ mobilization. 
TABLE 7. Stability Constants of Ni-Fulvic Acid Complexes

\begin{tabular}{|l|l|l|l|l|}
\hline FULVIC ACID & METHOD & TEMPERATURE & MEDIUM & LOG OF EQUILI BRIUM CONSTANT \\
\cline { 2 - 6 } & & & $\mathrm{PH} \mathrm{3.5}$ & $\mathrm{K}_{1} 3.45-3.48$ \\
oth $^{51}$ & 20 & & $\mathrm{~K}_{1} 4.13-4.16$ \\
& & & $\mathrm{~K}_{1} 5.14 \quad$ LAKE WATER \\
& & & $\mathrm{K}_{1} 4.32-5.64$ PEAT \\
& & & $\mathrm{K}_{1} 3.1 \quad$ SOIL \\
\hline
\end{tabular}




\section{TECHNETIUM-ORGANIC COMPLEXES}

AQUEOUS COMPLEX STABILITY

Technetium in aqueous solution is commonly found in the +7 oxidation station as $\mathrm{TcO}_{4}^{-}$(pertechnetate). (52) Tc(VII) exhibits no aqueous cationic chemistry ${ }^{(22)}$ but tetrahedral $\mathrm{TCO}_{4}^{-}$is very stable in alkaline solution. (53) Pertechnetate can be reduced to a lower oxidation by various acids and organics to form a multiplicity of organic oxidation products. ${ }^{(54)}$ These acids and organics include $\mathrm{HCl}$ and thiocyanate ion, ${ }^{(55)}$ organic impurities in tetraphenylarsonium chloride, anion exchange resin, and some organic solvents. Reduced TC(IV) is present in aqueous solution as $\mathrm{TCO}^{2+}$ at $\mathrm{pH} \leq 1.2$, as $\mathrm{TCO}(\mathrm{OH})^{+}$ at $\mathrm{pH} 1.5-2.0$ as $\mathrm{TCO}(\mathrm{OH})_{2}$ or $\mathrm{TCO}_{2} \cdot \mathrm{OH}_{2}$ at $\mathrm{pH}>2 .(56)$

Although $\mathrm{TCO}_{4}^{-}$will not complex with organics, the complexation of technetium (IV) and technetium (V) is well known. Technetium will complex with ascorbic acid when reduced by thiocyanate. ${ }^{(57)}$ Technetium (VII) on $\mathrm{Fe}(\mathrm{OH})_{2}$ in $\mathrm{HCl}$ is reduced at $\mathrm{pH}$ 1.5-2.8 and complexes with DTPA and EDTA. (58) Technetium (VII) is reduced in the presence of Sn(II)-DTPA to the +4 oxidation state and complexes with DTPA to form TC-DTPA. $(59,50)$ Table 8 lists some stability constants which were obtained for technetium-organic ligand complexes in a constant reducing atmosphere and constant $\mathrm{pH}$. The stability constants are very high. ${ }^{(61)}$

TABLE 8. Stability Constants of Technetium Complexes

\begin{tabular}{|c|c|c|c|c|}
\hline & Method & Temperature & Medium & $\begin{array}{l}\text { Log of } \\
\text { Equilibrium Constant }\end{array}$ \\
\hline NTA ${ }^{3-}$ & $i x$ & $25^{\circ} \mathrm{C}$ & $\begin{array}{l}0.7 \mathrm{M} \mathrm{HClO}_{4} \\
\mathrm{pH} \quad 1.5-2.0\end{array}$ & $K_{1} 13.8 K_{2} 25.7$ \\
\hline EDTA $^{4-}$ & $i x$ & $25^{\circ} \mathrm{C}$ & $0.7 \mathrm{M} \mathrm{HClO}_{4}$ & $k_{1} 19.1$ \\
\hline DATA ${ }^{4-}$ & $i x$ & $25^{\circ} \mathrm{C}$ & $0.7 \mathrm{M} \mathrm{HClO}_{4}$ & $\mathrm{~K}_{7} 20.7$ \\
\hline DATA $^{4-}$ & $i x$ & $25^{\circ} \mathrm{C}$ & $0.1 \mathrm{M} \mathrm{HClO}_{4}$ & $\mathrm{~K}_{7} 20.8$ \\
\hline
\end{tabular}


AQLEOUS COMPLEX STABILITY IN SOIL SYSTEMS

Inorganic pertechnetate is absorbed very little by soil. (16) The pH and organic carbon content of the soil are the major variables which affect retention of Tc. Two other investigators attribute technetium absorption by soil to microbial activity. $(53,62)$ One investigator found that 98 percent of technetium is absorbed within 2 to 5 weeks by eight out of eleven soils and sterilization of the soil eliminated this absorption.

Because of the dearth of information which is available on technetium organic complexes, it is impossible to confidently predict their elution and absorption properties in soils. More work is needed on the stability of technetium complexes at high $\mathrm{pH}$ in the absence of reducing agents over a long period of time. The reaction of these complexes with soil will then need to be investigated. 


\section{SUMMARY}

Zirconium, niobium, nickel and possibiy technetium are mobile in the presence of aqueous organic complexing agents to a certain extent given sufficient organic materials and assuming a formation mechanism. Low pH appears to be required for efficient complex formations with organic ligands in aqueous media. Zirconium complexes with a number of synthetic chelating agents such as EDTA, and DTPA to form stable, water-soluble complexes in acidic and neutral aqueous systems. Zirconium also complexes with HIMDA or HXG to form a stable, water soluble complex in any aqueous system and with $\alpha$-hydroxy carboxylic acids in alkaline aqueous systems. Uncomplexed zirconium would be readily absorbed by or precipitated on soil. Although the results of interaction of zirconium organic complexes with soil are generaliy unknown, one would predict that these complexes would be absorbed less by soil than uncomplexed zirconium.

Niobium generally forms the most stable complexes with nitrogen containing chelating ligands such as EDTA, and less stable complexes with $\alpha$-hydroxy carboxylic acids and monodentate ligands. Uncomplexed niobium would be efficiently absorbed by or precipitated on soil from aqueous systems. Despite the high stability constants of complexed niobium one would predict that organic complexes of niobium would be absorbed by soil because of hydrolysis of complexed niobium to insoluble hydrous niobium oxide.

Nickel complexes strongly with a number of oxygen and nitrogen containing organic ligands. Uncomplexed nickel is absorbed by soil in acidic and neutral aqueous systems and precipitated on soil in alkaline aqueous systems. Two complexes of nickel are known to be absorbed to a much lesser extent by soil (Ni-DTPA, Ni-EDTA). FuTvic acid and synthetic chelating agents are known to greatly enhance the movement of nickel in soil and to reduce $\mathrm{Ni}$ absorption by soit.

Technetium complexes with organic ligands in a reducing environment but the behavior of these complexes in a nonreducing environment is unknown. Therefore, al though technetium (VII) is absorbed only little by soil, further work is needed to characterize the interaction of lower-valent Tc complexes with soil. 


\section{RECOMMENDATIONS}

Several approaches can be taken to control the movement of organic zirconium, niobium, technetium, or nickel complexes depending essentially on present water content and predicted water content of the surrounding soi 1 . Construction of a barrier between buried waste and the ground surface to prevent rainwater percolation eliminates the principal mode of migration by avoiding saturation by rainwater. Choice of an arid land site with no potential of breakthrough of groundwater or other interaction with aquafers is absolutely essential.

Since the uncomplexed radionuclides except technetium are far less mobile than the complexed radionuclides, movement of radionuclides through soil could be reduced merely by containing sources of organic ligands. One method would be to entirely prohibit the burial of organic chelating agents. The containment of organic material in acid resistant canisters would also effectively reduce radionuclide movement. A source of decomposing organic matter would thus be eliminated. (Some burial procedures are currently employing this).

Finally, organic material could be eliminated by digestion in oxidizing media or by incineration. Technetium would remain water soluble and possibly volatile (as $\mathrm{Tc}_{2} \mathrm{O}_{7}$ ). Niobium, zirconium and nickel would be rendered water insoluble and resistant to organic complexation with greatiy reduced mobility in soil media. 


\section{REFERENCES}

1. J. E. Mirabella, Summary of Radioactive Solid Waste Burials in the 200 Areas During First Half of 1976, ARH-CD-744 2Q, November 10, 1976.

2. Waste Management Operations, Hanford Reservation, Richland, Washington, ERDA - 1538, December 1975.

3. M. J. Be11, Origen, ORNL-4628, May 1973.

4. C. W. Kee, A. G. Croff and J. 0. Blomeke, Updated Projections of Radioactive Wastes to be Generated by the U.S. Nuclear Power Industry, ORINL-TM-5427, December 1976.

5. D. W. Bensen, Review of Soil Chemistry Research at Hanford, HW-67201, General Electric Co., Hanford Atomic Products Operation, Richland, Washington, August 10, 1960.

6. J. Haia, The Aqueous Chemistry of Zirconium and Hafnium, UJV 1066/64, institute of Theoretical and Physical Chemistry of University, Brno and Nuclear Research Institute, Czechoslovak Academy of Sciences, Prague, 1964.

7. Radiological Health Handbook, U.S. Department of Health, Education and Welfare, January 1970.

8. F. J. Stevenson, "Gross Chemical Fractionation of Organic Matter," Methods of Soil Analysis, Part 2, C. A. Black, et al., eds., American Society of Agronomy, Madison, Wisconsin, pp. 1409-1421, 1965.

9. A. D. McLaren, G. H. Peterson, Soil Biochemistry, Marcel Dekker, Inc., New York, 1967.

10. W. Stumm, J. T. Morgan, Aquatic Chemistry: An Introduction Emphasizing Chemical Equilibria in Natural Wastes, Wiley-Interscience, New York, 1970.

11. M. Schnitzer, S. U. Kahn, Humic Substances in the Environment, Marcel Dekker, Pub., New York, 1972.

12. A. E. Martell (compiler), Stability Constants of Metal Ion Complexes Section II, Spec. Pub. No. 17, The Chemical Society, Burlington House, London, 1964.

13. A. E. Marte11 (compiler), Stability Constants of Metal ion Complexes Supplement \#1, Part II, Spec. Pub. No. 25, The Chemical Socieyt, Burlington House, London, 1971.

14. J. L. Nelson, Soil Column Studies with Radiostrontium II Effects of Soil Column Length and Diameter, HW-63930, General Electric, Hanford Laboratories Operation, Richland, Washington, 1959. 
15. J. L. Nelson, Soil Column Studies with Radiostrontium I Effects of Temperature and of Species of Accompanying Ion, HW-62035, General Electric, Hanford Laboratories Operation, Richland, Washington, 1959.

16. R. E. Wildung, R. C. Routson, R. J. Serne, T. R. Garland, Pertechnetate, Iodide, and Methyl Iodide Retention by Surface Soils, BNWL-SA-5195, Battelle Northwest Laboratories, Richland, Washington, October 9, 1974.

17. D. W. Rhodes, "The Effect of $\mathrm{pH}$ on the Uptake of Radioactive Isotopes from Solution by a Soil," Soil Science Society Proceedings, pp. 389-392, 1957.

18. R. J. Serne, R. C. Routson, D. A. Cochran, Experimental Methods for Obtaining Percol Model Input and Verification, BNWL-1721, Battelle Pacific Northwest Laboratories, Richland, Washington, 1973.

19. M. Reeves, C. W. Francis, 3. 0. Duguid, Quantitative Analysis of Soil Chromatography I. Water and Radionuclide Transport, Oak Ridge National Laboratory, Oak Ridge, Tennessee.

20. R. C. Routson, R. J. Serne, One-Dimensional Model of the Movement of Trace Radioactive Solute through Soil Columns: The Percol Model, Battelle Northwest Laboratories, Richland, Washington, BNWL-1718, 1972.

21. J. C. Bailar, Jr. (ed.), The Chemistry of Coodination Compounds, Reinhold Pub. Corp., New York, 1956.

22. F. A. Cotton, G. Wilkinson, Advanced Inorganic Chemistry, Interscience Pub., New York, 1972.

23. W. B. Blumentha1, The Chemical Behavior of Zironium, D. Van Nostrand Co., Inc., New York, p. 337, 1958.

24. B. J. Intorre, A. E. Marte11, "Zirconium Complexes in Aqueous Solution I. reaction with Multidentate Ligands," J. Am. Chem. Soc, Vol. 82 , pp. 358-364,' 1960 .

25. B. J. Intorre, A. E. Marte11, "Aqueous Zirconium Complexes II Mixed Chelates," J.Am. Chem. Soc., Vol. 83, pp. 3618-3623, 1961.

26. A. W. Ermakov, N. B. Kalinichenko, I. N. Marov, "Complex Formation by Zirconium and Hafnium with Tiron and Pyrocatechol," Russ. J. of Org. Chem., Vol. 12, p. 812, 1967.

27. Ts. B. Konunova, L. S. Kachkar, "Complex Formation by Zirconium and Hfnium with Hydroxycarboxylic Acids," Russ. J. Inorg. Chem., Vol. 15, p. $1543,1970$. 
28. D. I. Ryabchikov, A. W. Ermakov, V. K. Belyaeva, I. N. Marov, "Zirconium and Hafnium Complexes with Some Hydroxy Acids, Russ. J. Inorg. Chem., vol. 5, p. 505, 1960.

29. J. M. Korenman, F. R. Sheyanova, Z. M. Gureva, "Instability Constants of Complexes of Zirconium with Some Organic Ligands," Russ. J. of Inorg. Chem., Vol. 11, p. 1485, 1966.

30. H. V. Krishnamurty, G. M. Harris, "The Chemistry of the Metal Oxalato Complexes," Chem. Rev., Vol. 61, p. 213, 1961.

31. E. K. Dursma, Symposium on Organic Matter in Natural Waters, D. W. Hood, ed., University of Alaska, 1970.

32. I. M. Gibalo, Analytical Chemistry of Niobium and Tantalum, Ann Arbor Humphrey Science Publishers, Ann Arbor, 1970.

33. G. A. Volkova, V. G. Sochevanov, "Complex Formation by Niobium Hydroxide with EDTA," Russ. J. Inorg. Chem., Vol. 12, p. 222, 1967.

34. F. Fairbrother, J. B. Taylor, "Water-Soluble Complexes of Niobium and Tantalium. Part I. Complexes with Alpha-Hydroxy Acids and Amines," J. Chem. Soc., London, p. 4946, 1956.

35. F. Fairbrother, D. Robinson, J. B. Taylor, "Some Water-Soluble Complexes of Pentavalent Niobium and Tantalum," J. Inorg. and Nucl. Chem., Vol. 8, p. $296,1958$.

36. M. Qureshi, K. G. Varshney, R. C. Kaushik, "Cation Exchange Studies of $\mathrm{Ti}^{4+}, \mathrm{V}^{5+}, \mathrm{Fe}^{3+}, \mathrm{Nb}^{5+}$ and $\mathrm{UO}_{2}{ }^{2+}$ in Formic, Oxalic, Tartaric, and Citric Acid Media, Ana 1. Chem., Vol. 45, p. 2433, 1973.

37. L. J. Kirby, The Radiochemistry of Nickel, Nuclear Science Series, NAS-NS p. 3051,1961 .

38. N. N. Barkhanova, A. Ya Fridman, N. M. Dyatlova, "Mono- and Dinuclear Compounds Formed by Ethylenediaminetetraacetatio-compounds of iilickel, Cobalt, and Copper with Glycinate and 0xalate Ions in Solution," Russ. J. Inorg. Chem., Vol. 18, p. 227, 1973.

39. V. V. Grigoreva, S. M. Tsimible, "Composition and Relative Stability of Complex Cobalt and Nickel Compounds with Hydroxy Acids at pH 6.0," Visn. Kiiv, Univ. Ser. Khim., No. 11, pp. 17-23, 1970.

40. C. Panda, R. K. Patnaik, "Gluconate Complexes of Cobalt (11) and Nickel (11)," J. Indian Chem. Soc., Vol. 53, pp. 718-719, 1976. 
41. L. G. Joyce, and W. F. Pickering, "An Investigation of the Nickel Gluconate System," Augt. J. Chem., Vol. 18, pp. 783-794, 1965.

42. M. Bobtelsky and J. Jordan, "The Metallic Complexes of Titrates and Citrates, Their Structure and Behavior in Dilute Solutions. I. The Cupric and Nickelous Complexes," Am. Chem. Soc. J., Vol. 67, pp. 1824-1831, 1945.

43. N. N. Barkhanova, N. M. Dyatlova, A. Ya. Fridman, "Reactions of Coproportionation of Dinuclear Mixed Compounds of the Transition Metals with the Ethylenediaminetetra-acetate Ion and with Ethylenedianine, Glycine, and Oxalate in Solution," Russ. J. of Inorg. Chem., Vol. 18, p. 785, 1973.

44. M. Ya Chebotina, "Influence of Plant Extracts on the Mobility of Iron 59 and Cobalt 60 in Soil Under Conditions of Dynamic Laboratory Experiments", Soviet Radiochemistry, Vo1. 13, pp. 756-759, 1971.

45. N. V. Kulikov, "Influence of Certain Complexions of Radioisotope Sorption by Soi1", Tr. Inst. Ekol. Rast. Zhivotr., Vol. 61, pp. 21-25, 1968.

46. Arthur Wallace, Behavior of Certain Synthetic Chelating Agents in Biological Soil Systems, Annual Progress Report, AEC Contract AT(04-3)-34 Project \#51, Univ. of Cal., Riverside, Cal., 1973.

47. M. Ya Chebotina, "On the Properties of Desorptive Effects of Extracts on Leaf Fal1", Tr. Inst. Exol. Past. Zhivotn., Vol. 61, pp. 12-21, 1968.

48. Kabata-Pendias, "Notes on Chemical Methods of Determining Available Copper and Cobalt in Soils", Pas. Pulaukski, Vol. 5, pp. 31-39.

49. M. Schnitzer, "Reactions Between Fulvic Acid, a Soil Humic Compound and Inorganic Soil Constituents", Soil Sci. Soc. Amer. Proc., Vol. 33, p. $75,1969$.

50. M. Schnitzer, S. I. M. Skinner, "Organic-Metallic Interactions in Soils: 7. Stability Constants of $\mathrm{Pb}^{++}, \mathrm{Ni}^{++}, \mathrm{Mn}^{++}, \mathrm{Co}^{++}, \mathrm{Ca}^{++}$and $\mathrm{Mg}^{++}$- Fulvic Acid Complexes", Soil Science, Vol. 103, p. 247, 1967.

51. R. F. C. Mantoura, J. P. Riley, "The Use of Gel Filtration in the Study of Metal Binding by Humic Acids and Related Compounds", Analytica Chimica Acta, Vol. 78, pp. 193-200, 1975.

52. K. V. Kotegov, 0. W. Paviov, V. P. Shvedov, "Technetium", Advances in Inorganic Chemistry and Radiochemistry, H. J. Erulins, A. G. Sharpe, eds, Vo1. 2, Academic Russ, N. Y., 1968.

53. E. R. Landa, "The Behavior of Technetium-99 in Soils and Plant", Diss. Abstr. Int. B., Vol. 37, p. 142, 1976. 
54. E. Anders, The Radiochemistry of Technetium, NAS-NS-3201, Nuclear Science Series, 1960.

55. R. Colton, The Chemistry Rhenium and Technetium, Interscience Pub., N. Y., 1965.

56. B. Gorski, H. Koch, "Zur Chimie des Technetium in Wäbriger Lösung-I über Den Zustand Des Vierwertigen Technetium in Wäbriger Lösung", J. Inorg. Nucl. Chem., Vol. 31, pp. 3565-3571, 1969.

57. Shin-Hwa Yeh, J. P. Kriss, "Distribution and Scintiphotography of a New Complex Pentavalent Technetium-99 in Citrate", J. Nucl. Med., Vol. 8, pp. 666-677, 1967.

58. V. Virana, I. Kleisner, J. Cechova, "Preparation of Complexes of DTPA and EDTA with Technetium-99m with a High Specific Activity", Cas. Lek, Cesk. Vol. 112, pp. 467-470, 1973.

59. L. Merlin, M. Bresnard, Y. Cohen, "Chemistry of Technetium. Effect of Oxidoreduction Systems on the Stability of Complexes Used as Radiopharmeceuticals", Radiopharm. Label. Compounds, Proc. Symp., Vol. 1, pp. 63-70, 1973.

60. L. O. M. J. Smithius, J. B. F. Spijkers, "Preparation of a Technetium99m-DTPA-Complex and Its Use in Nuclear Medicine", Pharm. Weekbl, Vol. 108, pp. 217-222, 1973.

61. B. Gorski, H. Koch, "Uber die Komplex Bildung Von Technetium Mit Chelatbildenden Liganden-II", Inorg. Nucl. Chem., Vol. 32, pp. 3831-3836, 1970.

62. R. G. Gast, Behavior Technetium-99 in Soils and Plants, Contract AT (11-1)-2447, Minnesota University, St. Paul, Min., 1976. 


\section{DISTRIBUTION}

No. of

Copies

OFFSITE

1 DOE Chicago Patent Group 9800 South Cass Avenue Argonne, IL 60439

A. A. Churm

1 DOE Sponsoring Division Washington, D.C. 20545

James G. Steger

27 DOE Technical Information Center

20 ORNL Information Center Ecological Sciences Information Center

Helen A. Pfuderer

Building 2029

P.0. Box $X$

ORNL 37830
No. of

Copies

ONSITE

2 DOE Richland Operations Office Programs Division

H. E. Ransom

Bruce Guilbeault

Battelle-Northwest

A. M. Platt

Steve Phillips

Technical Information Files (5)
Danpat Rai
Jeff Serne
John Relyea
R. E. Nightingale
P. C. Walkup
J. A. Franz
D. J. Wiggins
J. M. Duguid
Technical Publications 


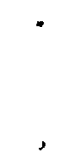

